\title{
AISLAMIENTO E IDENTIFICACION DE BACTERIAS FOTOSINTETICAS EN EL MONIMOLIMNION DEL ESTANY DE CULLERA (VALENCIA)
}

\author{
R. Mondragón, E. Vicente y J.J. Guillenea \\ Departamento de Microbiología. Facultad de Ciencias Biológicas. Universidad de Valencia
}

Palabras clave: Meromictic coastal lagoons, photosynthetic bacteria, lagoon of Cullera (Spain).

\begin{abstract}
ISOLATION AND IDENTIFICATION OF PHOTOSYNTHETIC BACTERIA FROM THE MONIMOLIMNION OF "THE ESTANY OF CULLERA" (VALENCIA)

The Estany of Cullera is a coastal lagoon with a tendency to stratification. In the year of the study was meromictic, consisting in two distinct waters layers: freshwater of fluvial origin in the surface and marine water in the bottom.

The high contents of sulphide in the anoxic marine water layer, makes possible the growth of important populations of photosynthetic bacteria, that in summer present two density maxima: one in the chemocline and another near the bottom. The dominant organism in these maxima was identified as Chlorobium pbaeotibriodes. Other phototrophic bacteria have been isolated from these water layers, using enrichment techniques based on the modification of the concentration of sulfide, $\mathrm{pH}$ and ligth intensity and spectra, as well as isolation in solid mediurn. These bacterial strains were identified in axenic cultures by means of the absortion spectra of their pigments, morphology and ultrastructure as pertaining to the species Cblorobium limicola. Chromatium vinosum and Rhodomicrobium v'annielli. The presence of Thiospirillum sp. was also observed but axenic cultures for its study and identification could not be obtained.

The environmental conditions characteristic of the chemocline of this lagoon determine a notorious and constant dominance of Chlorobium pbaeotibrioides over all the other photosynthetic bacteria that are always in low number. Only in early summer, an important growth of Chlorobium limicola is apparent, and it is possible to observe a green water layer in the chemocline, just above the brown layer of Chlorobium pbaeotibrioides.
\end{abstract}

\section{INTRODUCCION}

En estuarios cerrados y lagunas litorales con flujo de agua dulce superficial, cuando la profundidad lo permite, se establece con frecuencia una picnoclina, capaz de separar por una quimioclina estable, una zona monimolimnética donde se agota eloxígeno y un mixolimnion oxigenado.

La presencia de sulfuro de hidrógeno en el monimolimnión de estas lagunas, procedentes mayormente de la reducción de sulfatos, posibilita el desarrollo de grandes poblaciones de bacterias fototrofas del azufre, siempre que dispongan de una intensidad luminosa suficiente en estas zonas anóxicas del lago

Limnética 1: 78-85(1984)

() Asociación Espanola de Limnología, Madrid. Spain
(Pfennig, 1967).

Estas bacterias fotosintéticas forman con frecuencia una capa en la quimioclina de los lagos meromícticos, debido entre otras causas al efecto de autosombra, pero en ocasiones los fotosintéticos bacterianos se extienden a todo el monimolimnion con densidades variables. En algunos lagos mesotróficos someros se encuentran formando una fina película en contacto con el sedimento (Czeczuga, 1968), mientras que bajo espciales condiciones hidrográficas, particularmente en cuencas pequeñas, las bacterias invaden todo el cuerpo del agua..Esto último puede 
observarse en la laguna del Sisó, pequeña charca integrante del sistema cárstico de Banyoles (Guerrero et al. 1980)

Las bacterias fotosintéticas no sulfúreas (Rhodospirillaceae) se encuentran ampliamente distribuídas en la naturaleza y es difícil recoger muestras del fondo o de la masa de agua en las que por métodos de enriquecimiento no se pueda demostrar su presencia (Van Niel, 1944). Sin embargo, no se han encontrado acumulaciones de Rhodospirillaceue corno las que presentan las bacterias verdes $y^{\prime}$ púrpuras del azufre, a pesar de que con bajas concentraciones de sulfuro algunas especies pueden utilizarlo como dador de electrones (Hansen \& van Gemerden, 1972). Las especies de esta familia aisladas de medios marinos, usan el sulfuro y el tiosulfato mucho mejor que las cepas de agua dulce, probablemente como adaptación a la fuerte reducción de sulfatos en los ambientes costeros (Imhoff, 1979),

\section{MATERIAL Y METODOS}

El lago: el Estany de Cullera es una laguna litoral meromíctica situada en las cercanías de la ciudad de Cullera (Valencia), formada por el cierre de un antiguo estuario fluvial mediante una barra arenosa que delimita en conjunto una cubeta alargada de unos tres kilómetros de longitud y 400 a 500 metros de anchura media. La profundidad máxima es de 7 metros en la zona central y la media de 4 metros. Los aportes fluviales determinan un flujo superficial de agua dulce que discurre sin mezclarse con el agua salada de origen rnarino que penetra a través de la barra arenosa y que la subyace hasta el fondo de la cubetal La circulación típica de un estuario positivo que se presenta $\mathrm{c}$ esta laguna, determina la presencia constante de una cuña de agua saluda más densa que se cxticride por el fondo con un espesor de 3 '5 a 4 '5 metros. Esta cuña salina está separada por una fuerte picnoclina de agua dulce superficial con la que se mezcla en la zona de contacto formando iin gradiente. La presencia de esta picnoclina impide una mezcla importante de ambos sistemas y determina la formación de una quimioclina que separa la zona profunda y anóxica de la laguna (monimolimnion) de su parte más superficial oxigenada (mixolimnion), con la fuerte variación de los parámetros físico. químicos y biológicos que esta estratificación conlleva (Fig. 1)
Métodos experimentales: Las muestras para el aislamiento de las bacterias fototrofas se han obtenido extrayendo agua de la profundidad adecuada, desde la quimioclina situada aproximadamente a 4'5 metros hasta el fondo ( 7 metros), y según la precisión requerida se ha utilizado una botella limnológica de Ruttner de 2'6 litros de capacidad o un sistema de bombeo peristáltico semejante al utilizado por Cohén et al. (1977) en el Solar Lake, a fín de minimizar la distorsión de las capas bacterianas.

Medios de cultivo.

Para las bacterias verdes y rojas del azufre se usó como base el medio de Pfennig (1965) con algunas modificaciones sugeridas por el Dr. H. van Gemerden (comunicación personal) y cuya composición final es la siguiente: $\mathrm{NH}_{4} \mathrm{Cl}, 300 \mathrm{mg} / 1 ; \mathrm{KH}_{2} \mathrm{PO}_{4} \cdot 3 \mathrm{H}_{2} 0,100$ $\mathrm{mg} / 1 ; \mathrm{MgCl}_{2} \cdot 6 \mathrm{H}_{2} \mathrm{O}, 200 \mathrm{mg} / 1 ; \mathrm{CaCl}_{2} \cdot 2 \mathrm{H}_{2} \mathrm{O}, 200 \mathrm{mg} / 1$; $\mathrm{KCI}, 100 \mathrm{mg} / \mathrm{l}$; vit. $\mathrm{B}_{12}, 20 \mu \mathrm{g} / \mathrm{l}$; solución de elementos traza (SL-4) (Pfennig \& Lippert, 1966), $10 \mathrm{ml} / 1$; $\mathrm{Na}_{2} \mathrm{CO}_{3}, 2 \mathrm{~g} / \mathrm{l} ; \mathrm{Na}_{2} \mathrm{~S} .9 \mathrm{H}_{2} 0,240-480 \mathrm{mg} / \mathrm{l}$ y HCI $1 \mathrm{~N}$, $20 \mathrm{ml} / \mathrm{l}$. El pH final se ajustóen un rango de 7 a 8 . Por tratarse de bacterias procedentes de ambientes marinos se ha adicionado al medio $20 \mathrm{~g} / \mathrm{l}$ de $\mathrm{NaCl}$ y también, e n algunos casos, se ha supleme ntado con $250 \mathrm{mg} / \mathrm{l}$ de acetato sódico como fuente adicional de car bono.

Para las bacterías rojas no sulfúreas se ha utilizado el medio propuesto por Biebl \& Pfennig (1981), cuya composición es: $\mathrm{NH}_{4} \mathrm{Cl}, 300 \mathrm{mg} / \mathrm{l} ; \mathrm{KH}_{2} \mathrm{PO}_{4} \cdot 3 \mathrm{H}_{2} \mathrm{O}, 1$ $\mathrm{g} / \mathrm{l} ; \mathrm{CaCl}_{2} 2 \mathrm{H}_{2} \mathrm{O}, 50 \mathrm{mg} / \mathrm{l} ; \mathrm{MgCl}_{2} 6 \mathrm{H}_{2} \mathrm{O}, 100 \mathrm{mg} / \mathrm{l}$; $\mathrm{NaCl}, 200 \mathrm{mg} / \mathrm{l}$; solución de elementos traza (SL-4), $10 \mathrm{ml} / \mathrm{l}$; vit. $\mathrm{B}_{12}, 20 \mu \mathrm{g} / \mathrm{l}$; extracto de levadura, 200-300 $\mathrm{mg} / \mathrm{l}$; acetato sódico, $1 \mathrm{~g} / \mathrm{l} ; \mathrm{pH}$ final de 7,3.

\section{Identificación}

Utilizando técnicas de enriquecimiento basadas en la modificación de la concentración de sulfuro, $\mathrm{pH}$ e intensidad y tipo de espectro luminoso, así como aislamientos en medio sólido, se han obtenido colonias de diferentes bacterias fototrofas. Los cultivos puros han permitido su identificación siguiendo los criterios propuestos por Pfennig (1971, 1974) Y Mandel et al., (1971), basados principalmente en el estudio del espectro de absorción de sus pigmentos (bacterioclorofilas y carotenos), morfología, tamaño, movilidad y ultraestructura. 
El tipo de bacterioclorofila (Bchl.) y carotenos que posee cada especie se determinó mediante el espectro "in vivo" de una suspensión de bacterias y por extracción de los pigmentos con acetona $90 \%$, midiéndose espectrofotoinétricamente en este extracto las concentraciones de bacterioclorofilas y carotenos presentes (Yentsch, 1967; Gloe et al., 1975).

La morfología y tamaño de las bacterias se han determinado por observación en fresco bajo contraste de fases tanto de las muestras de campo, previamente concentradas por centrifugación, como de los cultivos de laboratorio.

\section{Microscopía electrónica}

Para la observación de la ultraestructura, las muestras fueron fijadas con glutaraldehídoe n tampón cacodilato ( $\mathrm{pH}=7,2$ ), durante dos horas y postfijadas con tetróxido de osmio ( $1 \%$ ) durante una noche a $4^{\circ} \mathrm{C}$. Tras ser deshidratadas con etanol y teñidas con acetato de uranilo, las muestras se incluyeron en araldita (Fluka).Los cortes obtenidos se contrastaron finalmente con citrato de plomo. Para la observación por tinción negativa, las muestras fueron depositadas sobre una rejilla recubierta de formwar y tratadas directamente con ácido fosfotúngstico $1 \%$ durante dos minutos

\section{Parametros físico-químicos y biológicos}

La temperatura y salinidad se determinaron con ayuda de un salinómetro de campo (Yelow Spring Inst. USA, modelo 33), y el pH y el potencial de óxido reducción mediante un medidor portátil (Radiometer 80), expresándose los valores obtenidos como sus correspondientes para la temperatura de $25^{\circ} \mathrm{C}$. Para la determinación del $\mathrm{O}$, disuelto se empléó el método de Winkler. La determinación del sulfuro se realizó por el método del azul de metileno, tras su precipitación en las muestras de agua con acetato de zinc $(220 \mathrm{~g} / 1)$ y $\mathrm{NaOH} 1 \mathrm{~N}$, (Trüper \& Schlegel, 1964). El número total de bacterias se determinó mediante recuento microscópico directo y la concentración de bacterias fotótrofas viables por diluciones seriadas en medio sólido contenido en tubos con tapón de rosca completamente llenos.

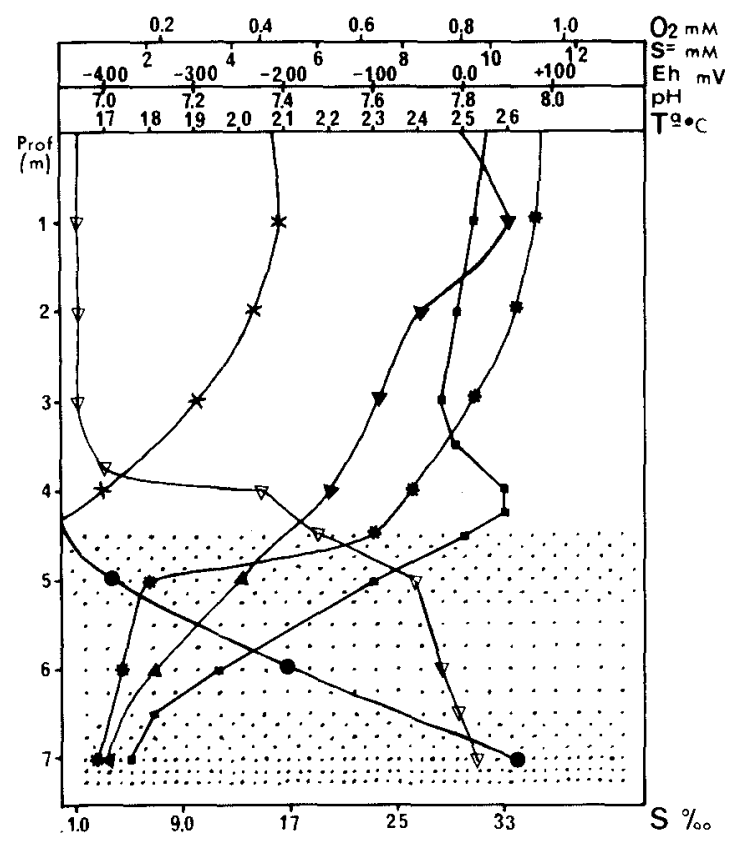

Fig 1 - Distribución vertical de algunos parámetros físico-químicos y su relación con las capas bacterianas en el Estany de Cullera, el día (24-8-82) El punteado muestra la distribución de las bacterias fotosintéticas - Temperatura; $\boldsymbol{\nabla}$ Salinidad; $\Delta \mathrm{pH} ; \boldsymbol{*}$ Eh: X Oxigeno; - Sulfuro - Verical profiles of some physico-chemical parameters in relation to the bacterial plates in the "Estany of Cullera" in august 24th., 1982 The shaded area shows the distribution of phorosynthetic bacteria - Temperature; $\nabla$ Salinity: A $\mathrm{pH} ;$ * Eh; X Oxygen; - Sulphide

\section{RESULTADOS}

La distribución vertical de los parámetros físicoquímicos en el lago nos permite situar la quemoclina alrededor de los 4,5 m (Fig. 1), pudiendo observarse cómo en esta zona se agota el oxígeno y aparece el sulfuro al tiempo que se produce un cambio brusco en el potencial de Oxido reducción, que pasa de oxidante a fuertemente reductor. Precisamente en esta quimioclina es donde aparecen las bacterias fototrofas, cuya distribución en el perfil del rnonimolimnion viene reflejada en la tabla 1 .

La figura 2 muestra los espectros de absorción de muestras de agua del lago tomadas a distintas profundidades con fecha de 24-8-82. Se observa cómo la especie predominante es Chlorobium phacotibrioides. especie de color pardo que 


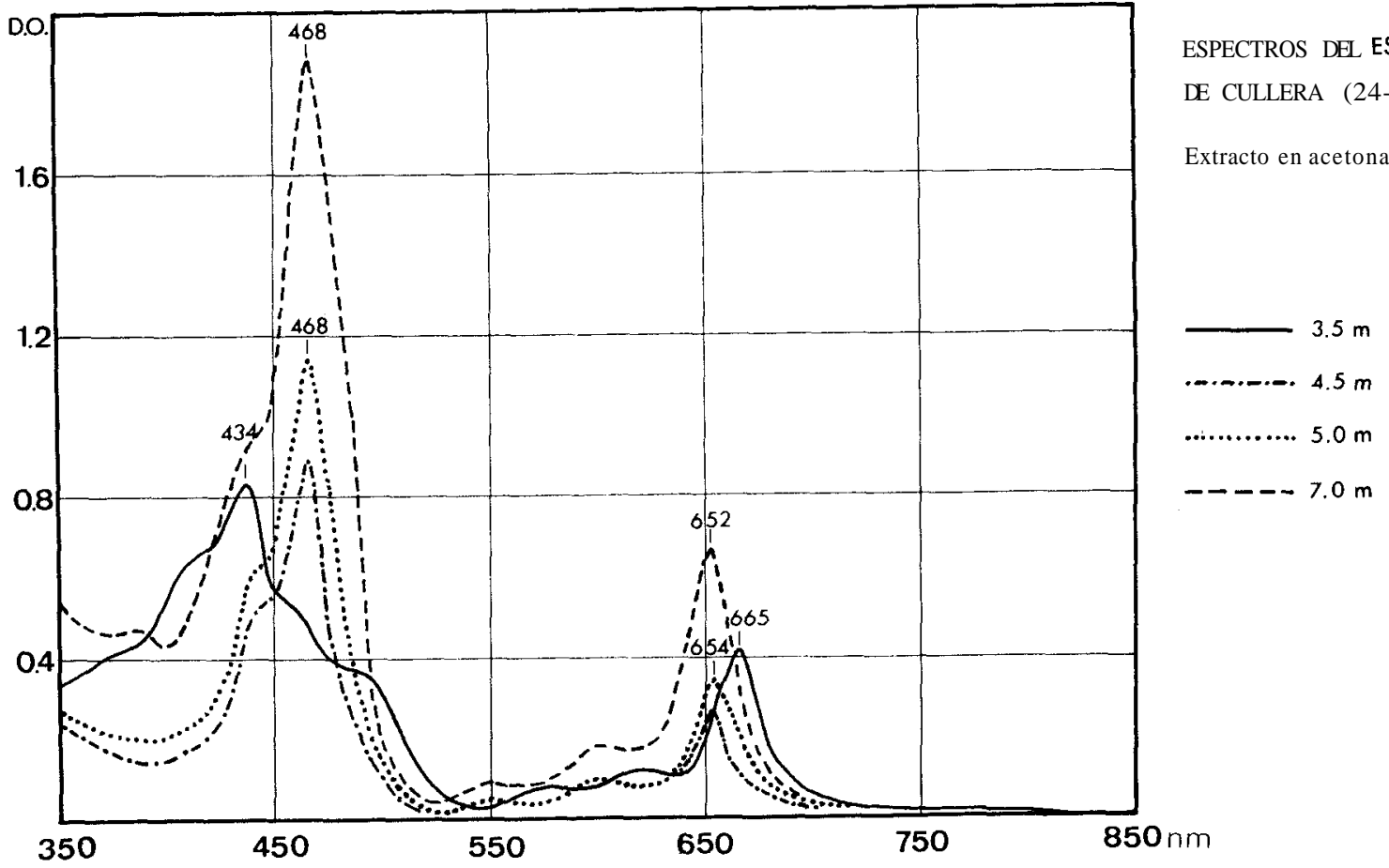

Figura 2.- Espectros de absorción de extractos acethnicos de los pıgmentos de muestras de agua de diferentes profundidades. Absortion spectra of the acetonic pigment extracts from samples of different dephs.

predomina a lo largo de todo el año. Cabe destacar la variación que existe en el contenido de Bchlee por célula, que aumenta con la profundidad debido al efecto de autosombra y por la necesidad de aprovechar al máximo la energía luminosa disponible.

Se han identificado cuatro especies de bacterias fototrofas, dos pertenecientes a la familia Cblorobiaceae: Cblorobium phaeoubrioides y Cblorobium limicola; una Chromatiaceae: Chromatium inosum: y una Rbodospirillaceae: Rhodomicrobium i'annielli.

La identificación de C. phaeovibrioides se ha efectuado a partir de su espectro de absorción (Fig. 3), que muestra la existencia de Bchl.e e isorrenierateno (caroteno típico de este grupo). También se ha atendido a su forma y tamaño y al estudio de su ultraestructura, que muestra la existencia de clorosomas o vesículas de Chlorobium dispuestos en la periferia de la célula por debajo de la membrana citoplasmática (Fig. 4).
El aislamiento de $C$. limicola no resulta fácil, ya que esta especie se encuentra generalmente desplazada por C. phaeovibrioides, excepto en una determinada época del año (aproximádamente en el mes de Julio). En esta época la disminución de la biomasa algal en el mixolimnion permite la penetración de la energía luminosa en zonas de espectro aptas para el desarrollo de este clorobium verde, que se sitúa en la parte superior del monímolimnión y por encima de la especie marrón. Los espectros de absorción, tanto de las suspensiones de células como de sus extractos acetónicos se muestran en la figura 3 .

El aislamiento de Chromatium vinosum presenta ciertas peculiaridades, dado que su presencia en el lago es mínima. Sembrando en un medio de cultivo apropiado agua de diferentes profundidades y con la ayuda de filtros que sólo permitían el paso de radiaciones del espectro rojo lejano e infrarrojo (el espectro de luz transmitida por el filtro presenta un máximo absoluto de $520 \mathrm{~nm}$. y un máximo relativo a 

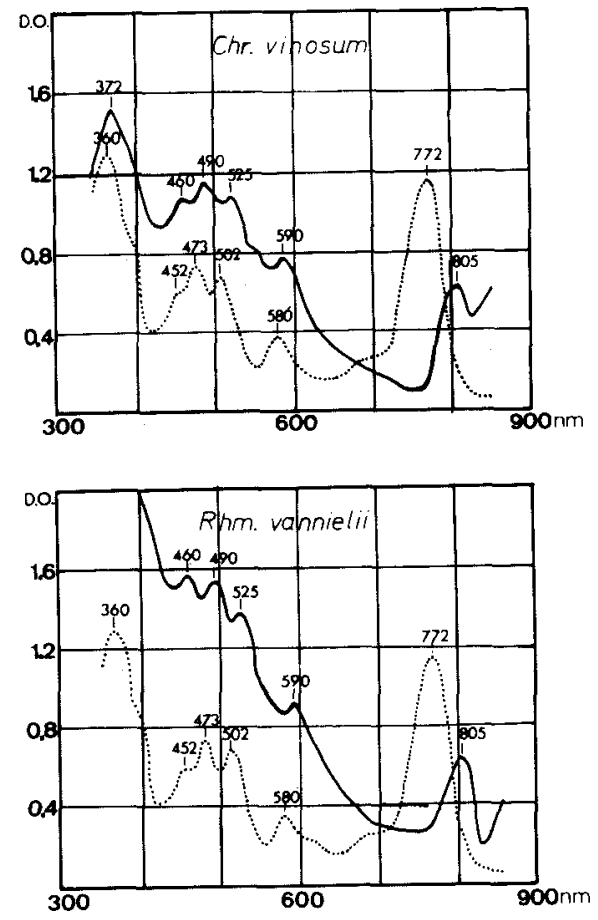
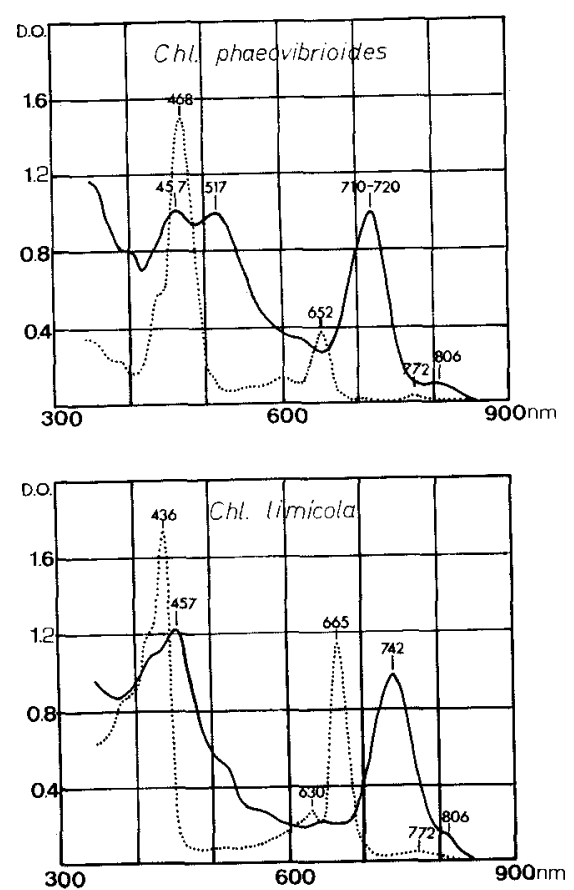

longitudes de onda de los máximos caracteristicos $(\mathrm{nm}$ ) Characteristic absorption maxima (nm)

$\begin{array}{lcc}\text { Espectro "in vivo" } & \begin{array}{c}\text { Espectro del extracto acetónico } \\ \text { "In vivo" spectrum }\end{array} & \begin{array}{c}\text { Spectrum of the acetonic extract } \\ \text { Bchl. a }\end{array} \\ \text { Bchl. c } & 805,590 & 665 \\ \text { Bchl. e } & 742 & 652 \\ \text { Clorobactene } & 710-720 & 436 \\ \text { Isorenieratene } & 457 & 468 \\ \text { Lycopene, Rhodopin } & 517 & 502.473,452\end{array}$

Figura 3.- Espectros de absorción de las diferentes bacterias fotótrofas aisladas de la quimioclina del "Estany de Cullera". Absortion spectra of rhe different phototrophic bacteria isolated from the chemocline of the "Esta ny of Cullera"

Tabla 1. Distribución vertical de diversos parámetros biológicos en el monimolimnion del "Estany de Cullera" CFU: unidades formadoras de colonias de Chlorobium phaeotibrioides. El isorenierateno se expresa en unidades arbitrarias (U A.). Vertical distribution of different biological parameters in the monimolimnion of the "Estany of Cullera" CFU: Colony Forrning Units of Chlorobium phaeotibrioides. The isorenieratene is expresed as arbitrary units (U.A.).

$\begin{array}{ccccc}\text { PROFUNDIDAD } & \text { CFU/lito } & \mu g \text { Bchle } e \text { litro } & \mu \mathrm{g} \text { Bchl. } e / C F U & \text { U A.Isoreniareteno/Litro } \\ 4.5 \mathrm{~m} & 04-0.6 \times 10^{*} & 1585 & 31.7 \times 10^{-8} & 39 \\ 5.0 \mathrm{~m} & 0.3-05 \times 10^{8} & 2215 & 55.3 \times 10^{-8} & 82 \\ 6.0 \mathrm{~m} & 08-1.0 \times 10^{4} & 5410 & 60.1 \times 10^{-8} & 17.5 \\ 70 \mathrm{~m} & 1.0-1.2 \times 10^{8} & 97.20 & 883 \times 10^{-8} & 338\end{array}$


Tabla II.- Resumen de las principales características sistemáticas de las bacterias fotosintéticas aisladas del "Estany de Cullera". IRT: isorenierato, CHL; clorobacteno, LY: lipoceno, $\mathrm{RH}$ : rodepeno.

Summary of the main systhematic characteristics of thephotosy nthetic bacteria isolated from the "Estany of Cullera". IRT: Isorenieratene, CHL: Chlorobactene, LY: Lycopene, RH: Rhodopin.

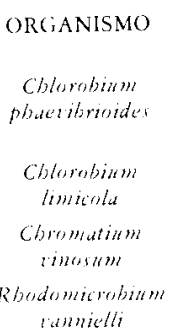

$$
\begin{gathered}
\text { Colur de lia célulits } \\
\text { en suspensión } \\
\text { MARRON } \\
\text { VERDE } \\
\text { MARRON-VERDE } \\
\text { MARRON-NARANJA }
\end{gathered}
$$

\begin{tabular}{|c|c|c|}
\hline Bichl. & Carotenos & $\begin{array}{l}\text { Aputalte) } \\
\text { Fotosintétici) }\end{array}$ \\
\hline e & IRT & CIOROSOMAS \\
\hline$c$ & $\mathrm{CHI}$. & CLOROSOMAS \\
\hline a & L.Y, RH & VESICUI.AR \\
\hline 1 & IY.RH & IAMEIAR \\
\hline
\end{tabular}

$$
\begin{aligned}
& \text { Forma y tamañ } \\
& \text { cilular } \\
& \text { VIBRION } \\
& 03.0 \text { f } \times 07.14 \mathrm{~cm} \\
& \text { BaCIIO } \\
& 07.11 \times 0.9-15 \mathrm{~nm} \\
& \text { BACIIO } \\
& 20 \times 2.56 \mathrm{~nm} \\
& \text { OVOIDE }
\end{aligned}
$$$$
1012 \times 20.28 \mathrm{nn}
$$

Agregadom
ESPIRAIES
CADENAS
NO
AGRIC; POR
GiMAC ION

$690 \mathrm{~nm}$, permitiendo el paso de longitudes de onda superiores a $800 \mathrm{~nm}$ ), se han podido aislar selectivamente colonias de C. vinosum. Otros factores de selección fueron una más baja concentración de sulfuro (2 mM) y un elevado rango de $\mathrm{pH}(8,0-8,5)$. La identificación se basó de igual manera en su espectro de absorción (Fig. 3) y en su ultraestructura (Fig. 5).

Por último, utilizando el medio descrito para las Rbodospirillaceae, se obtuvieron colinias rojas que se identificaron posteriormente como Rhodomicrobium vannielli (Fig. 3, 6 y 7).

\section{DISCUSION}

Las condiciones naturales específicas que se presentan en el monimolimnion de esta laguna (concentración de sulfuro, intensidad de luz, espectro luminosos, $\mathrm{pH}$, etc.), determinan un notorio y constante predominio de $C$. phaeovibrioides frente a las restantes bacterias fotosintéticas que sólo se encuentran en bajo número. Entre los dos clorobiums se establece una competenciaque se decanta a favor de una u otra especie según el espectro de luz que penetra hasta la capa de agua sulfhídrica, y que a su vez, se ve condicionado por la densidad algal existente en las zonas más superficiales del perfil vertical o por la presencia de una capa de Chromatium en un nivel superior (Montesinos et al., 1983). Aproximadamente en el mes de Julio dicha competencia se resuelve en una mayor presencia de Chlorobium limicola. Del mismo modo la competencia entre Chromatium y Cblorobium se resuelve en un equilibrio desigual en el que ninguna de las especies es eliminada totalmente,

Por último, el hecho de que Rhodomicrobium vannielli se aísle en medio no salino, presentando además dificultades para crecer en medio con similar salinidad a la del agua profunda del lago, connotaría su escasa importancia como posible colonizador de estos hábitats, a pesar de la capacidad que presenta esta especie para utilizar el sulfuro como dador de electrones (Hansen, 1974).

\section{BIBLIOGRAFIA}

Biebl, H. \& Pfennig, N. 1981. Isolation of members of the f. Rhodospirillaceae. In The Procaryotes (Starr $t$ al. eds) pags. 267273. Springer-Verlag. Berlin.

Cohen, Y; Krumbein, W.E. \& Shilo, M. 1977 Solar Lake (Sinaí), Limnol Oceanogr. 22: 69-620.

Czeczuga, B. 1968 Primary production of the sulfuric bacteria Thiopedia rosea Winogr. (Thiorhodaceae). Photosynthetica 2: 161-166

Gloe, A.; Pfennig, N.; Brokman, H \& Trowitzsch, W, 1975 A new bacteriochlorophyll from brown-colored Chhlorobiaceae. Arch, Microbiol. 102: 103-109

Guerrero, R.; Montesinos, E.; Esteve, I. \& Abella, C. (1980) Physiological adaptation and growth of purple and green sulfur bacteria in a meromictic lake (Vila) as compared to a holomictic lake (Sisó). Develop. Hidrobiol. 3: 161-171. Montesinos, E.; Guerrero, R.; Abella, C. \& Esteve I. 1983 Ecology and physiology of the competition for ligt between Chlorobium limicola and Chlorobium phaeobacteroides in natural habitats. App. Environ. Microbiol. 46: 1007-1016

Hansen, T.A. 1974 Sulfide als electronendonor voor 

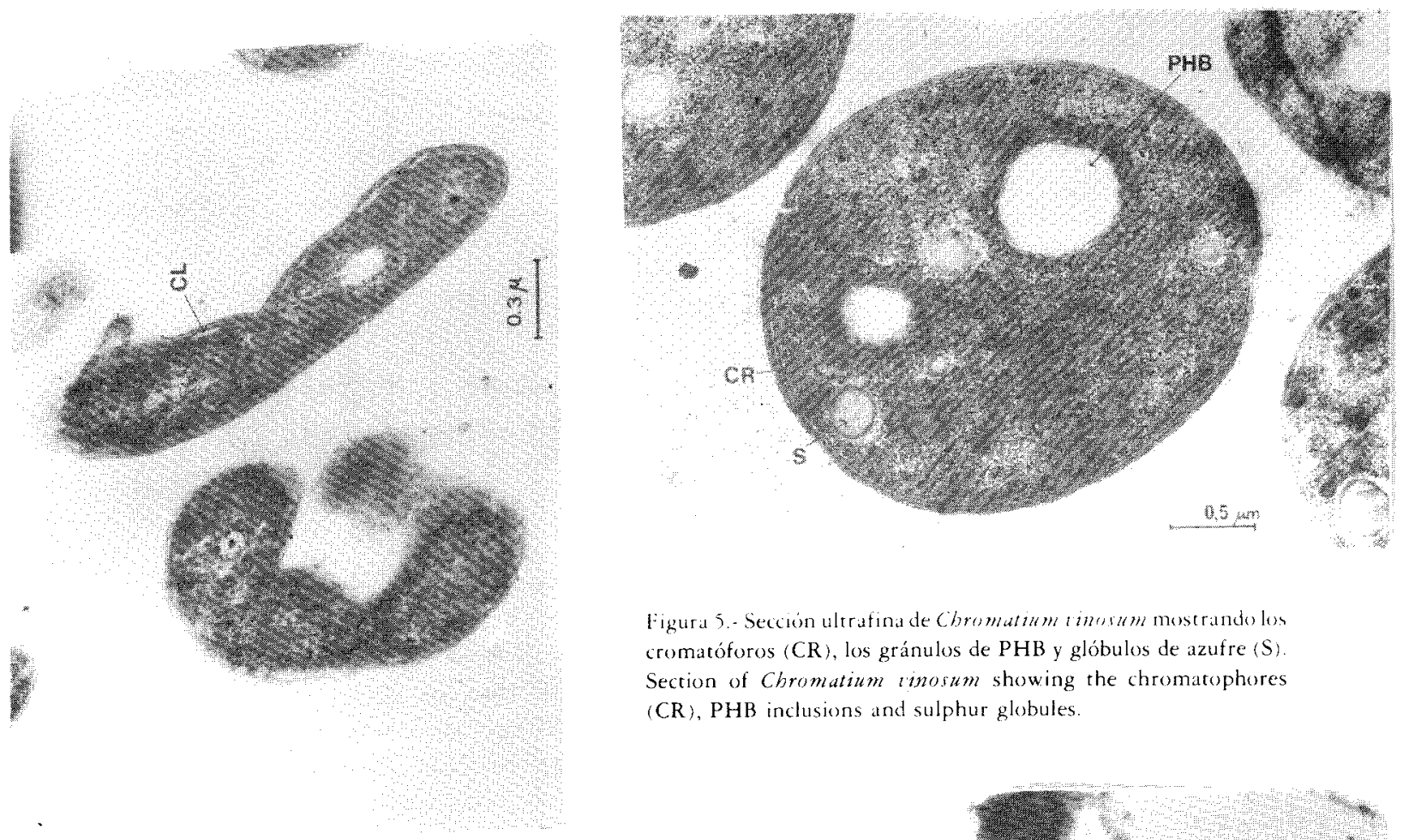

Figura 4.- Sección ultrafina de Chlorotiam placernibriosidel mostrando los clorosomas (CL). - Ulerastructure of Chlorrobium phacestibroider showing the chlorosomes (CL)

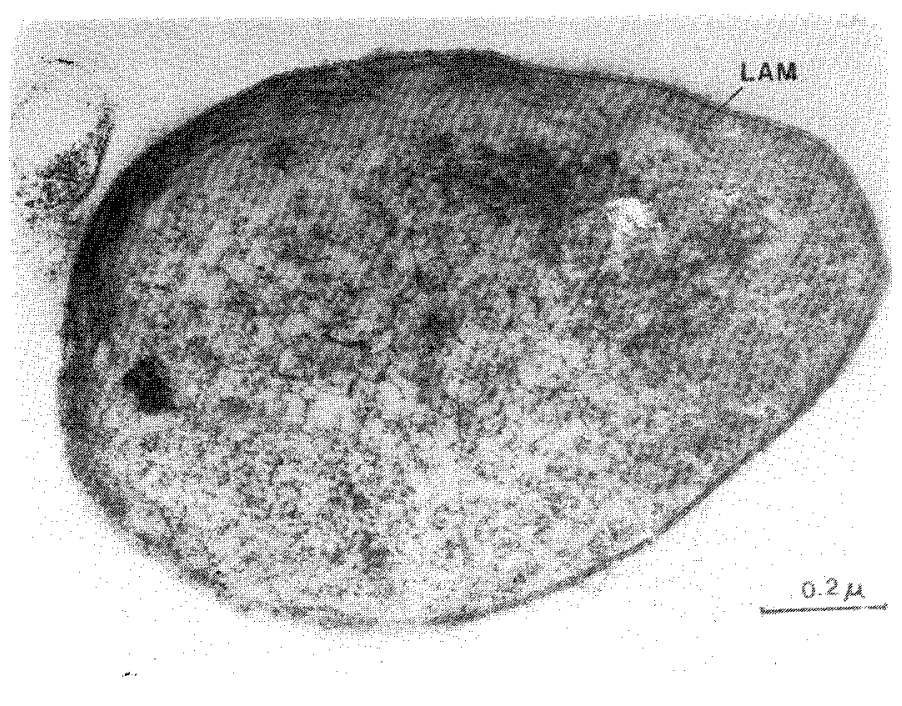

Figura 5. Sección ultrafina de Chromatium ainnam mostrando los cromaróforos (CR), los gránulos de PHB y glóbulos de azufre ( $S$ ). Secrion of Chromatium itnotum showing the chromatophores (CR), PHB inclusions and sulphur globules.

Figura 6." Sección ultrafina dt Rbadomicrobium rannicll mostrando el sistema lamelar de los cromatóforos (LAM) Ultrastructure of Rbodomicrobium 1 anniell showing the lamellar system of the chromatophores (LAM)

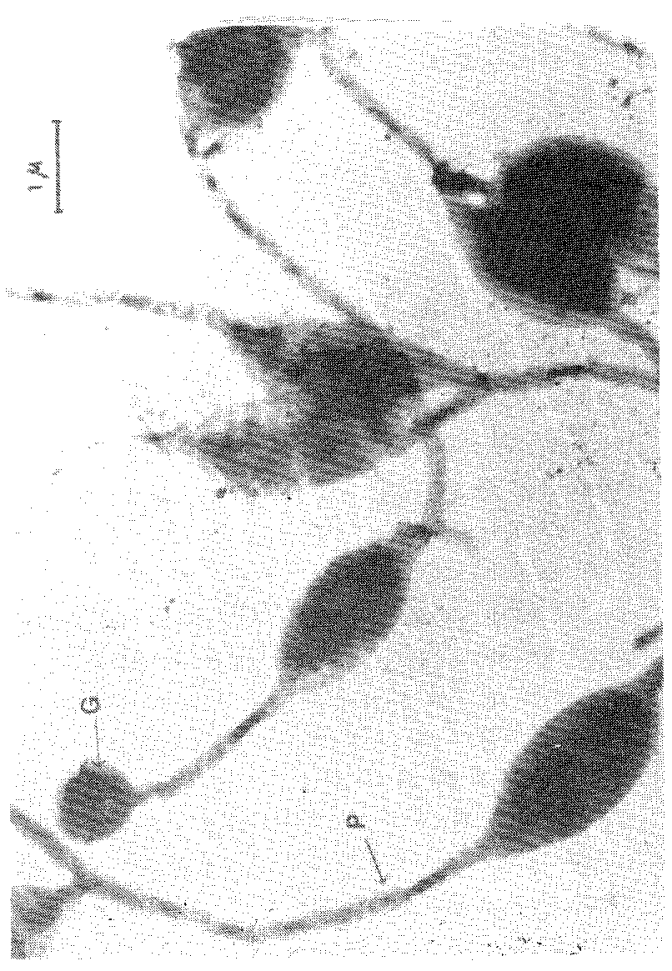

Figura - Microgratia electrónica de Rbodomacobum tannell (tinción negativa PTA $1 \%$ ) mostrando las prostecas (P) y las yemas $(G)$ - Electronic micrograph of Rbodomicrobium ranniell (negative stain PTA $1 \%$ ) showing prosrhecae (P) and buds ( $($ ) 
Rhodospirillaceae. Doctoral Thesis University of Groningen. Mandel, M.; Leadbetter, E.R. ;Pfennig, N. \& Truper, H.G. 1971 Deoxyribonucleic acid base composition of phorotrophic bacteria Int J. Syst. Bacterio. 21: 222-230

Pfennig, N. 1965 Anreicherungskulturen fü rore und grüne Schwefelbakterien. Zentr. Bakteriol. Parasitenk. Abt 1 Suppl. 1: 179-189

Pfennig, N. \& Lippert, K.D. 1966 Uber das Vitamin B12 Bedürfnis phototropher Schefelbakterien Arch. Microbiol. 55: 245-256

Pfennig, N, \& Truper, H.G. 1971a New nomenclarural combinations in thr phototrophic sulfur bacteria Int, J Syst. Bacteriol. 21:11

Pfennig, H. \& Trupper, H.G. 1971b Conservation of the family name Chromatiaceae Bavendamm 1924 with the type genus Chromatium Perty 1852, request for an opinion Int, J. Syst Bacterio. 21. 15

Pfennig, N. \& Trpper, H.G.1974 The phototrophic bacteria. IN Bergey's Manual of Determinative Bacteriology (Buchanan \&: Gibbon eds.): 24-64. Williams \& Wilkins. Baltimore

Pfennig, N. \& Truper, H.G. 1964 Sulphur metabolism in
Thiorhodaceae. I. Quantitative measuremenrs on growing cells of Chromatium okenii. Antonie van Leuwenhoek J. Microbiol. Serol. 30:225-238

Pfennig, N. \& Truper, H.G. 1981 Insolation of members of the f. Chromatiaceae and Chlorobiaceae, In The Procaryotes (Starr et al. eds.) pags. 279-289. Springer-Verlag. Berlin.

van Niel, C.B. 1944 The culture, general physiology, morphology and classification of the non-sulfur purple and brown bacteria. Bacteriol Rev. 8: 1.118

Yentsch, C, 1967 The measurements of chloroplastic pigments. Thirty years of progress? In Chemical environment in the aquatic habitat. (Golterman \& Clymo eds.) N.V. Noord-Hollandsche Vitgevers Maats-chappifj. Ansterdam. 